\title{
The Oxidation Mechanism of Aniline by Ozone Water and Ozone Micro-nano Bubble Water and Its Influencing Factors
}

\section{Zeming Xie}

Zhejiang Gongshang University

Jiali Shentu

Zhejiang Gongshang University

Yuyang Long

Zhejiang Gongshang University

Li Lu

Zhejiang Gongshang University

Dongsheng Shen

Zhejiang Gongshang University

Shengqi Qi ( $\sim$ qishengqi@zjgsu.edu.cn )

Zhejiang Gongshang University

\section{Research Article}

Keywords: aniline, ozone micro-nano bubble water, oxidation, pH, ion, pathway

Posted Date: January 10th, 2022

DOI: https://doi.org/10.21203/rs.3.rs-1137097/v1

License: () (1) This work is licensed under a Creative Commons Attribution 4.0 International License.

Read Full License 


\section{The oxidation mechanism of aniline by ozone water and ozone micro-}

\section{nano bubble water and its influencing factors}

Zeming Xie ${ }^{1}$, Jiali Shentu ${ }^{1,2}$, Yuyang Long ${ }^{1,2}$, Li Lu $^{1,2}$, Dongsheng Shen ${ }^{1,2^{*}}$, Shengqi Qi ${ }^{1,2^{*}}$

1 Zhejiang Provincial Key Laboratory of Solid Waste Treatment and Recycling, Zhejiang

Gongshang University, Hangzhou 310012, PR China

2 Instrumental Analysis Center of Zhejiang Gongshang University, Hangzhou 310012, PR China

${ }^{*}$ Corresponding author

\section{Abstract}

Aniline is a kind of refractory contaminant that is difficult to be degraded by microorganisms. Ozone is a green and efficient reagent to oxidize aniline, while the ozone oxidation efficiency is restricted by the low ozone mass transfer rate. Micro-nano bubble ozonation has been developed as a new method to significantly improve the ozone utilization rate, while the characteristics of ozone micro-nano bubble when compared with dissolved ozone is not clear. The paper carried out batch experiments to research the oxidation effect of aniline by ozone water $(\mathrm{OW})$ and ozone micro-nano bubble water (OMNBW), and found that the degradation rate of aniline by OMNBW was $2.8 \sim 5.9 \%$ higher than that by OW. The increase of $\mathrm{pH}$ had a negative effect on the degradation of aniline by $\mathrm{OW}$ and $\mathrm{OMNBW} . \mathrm{SO}_{4}{ }^{2-}, \mathrm{Cl}^{-}, \mathrm{HCO}_{3}{ }^{-}$and $\mathrm{Mg}^{2+}$ could inhibit the degradation efficiency by $0.04 \%, 0.99 \%, 0.44 \%$ and $10.4 \%$ for $\mathrm{OW}$, while the ratios were $1.1 \%, 6.4 \%, 4.1 \%$ and $1.5 \%$ for OMNBW. The addition of humic acid and fulvic acid could decrease the oxidation rate of aniline by $35 \%$ and $49 \%$ for OW, while the ratios were $41 \%$ and $62 \%$ for OMNBW. Through quenching experiment, it was found that the direct oxidation by ozone molecules and the indirect oxidation by superoxide radicals were main pathways for aniline oxidation by OW and OMNBW. This work provided a practical guide for the application of OMNBW in wastewater and groundwater treatment process.

Keywords: aniline, ozone micro-nano bubble water, oxidation, $\mathrm{pH}$, ion, pathway 


\section{Introduction}

Aniline is an important chemical material and widely used in dyes, pesticides, explosive materials, pharmaceuticals and other industries (Huang et al. 2017, Zhou et al. 2014). Aniline is used to synthesize pesticides, chemical brighteners, dyes, etc. It is also a common by-product of petroleum, papermaking and coal industry (ZabihiMobarakeh and Nezamzadeh-Ejhieh 2015). Aniline is mutagenic, teratogenic and carcinogenic, and has been listed as one of 129 priority-controlled pollutants by the U.S. Environmental Protection Agency (USEPA) (Trautwein et al. 2015). In addition, aniline is difficult to degrade and easy to maintain high toxicity even at low concentrations (Orge et al. 2017). Therefore, it is necessary to develop water treatment technologies to degrade aniline in order to meet the relative standards.

The remediation technology of polluted water included physical adsorption, biological process and chemical oxidation. However, for wastewater containing complex components, the efficiency of physical adsorption was very limited (Liu et al. 2009). For relatively persistent pollutants such as aniline, biological methods were inefficient and usually spent more time than chemical methods (Ikehata et al. 2008). Chemical oxidation was one of the most commonly used methods for water treatment by different reagents, such as Fenton reagent, potassium permanganate, persulfate and ozone. However, the oxidation efficiency of Fenton process was highly dependent on $\mathrm{pH}$ and was easily affected by the various substances in actual water, such as chloride and bicarbonate (Neyens and Baeyens 2003). In addition, hydrogen peroxide was unstable with a short half-life (Clarizia et al. 2017). Persulfate must be activated before it could be used for water treatment, but both catalyst and sulfate would produce a large number of by-products, resulting in secondary pollution (Hou et al. 2012). Chemical oxidation by permanganate would produce $\mathrm{MnO}_{2}$, which might also lead to secondary pollution (Li and Schwartz 2005).

Compared with other treatment technologies, ozone had been widely applied in 
the treatment of drinking water and reclaimed water (Miao et al. 2015, Shen et al. 2008), because it produced fewer secondary pollutants than other oxidants. When ozone was applied to oxidize contaminants in water, ozone gas was often injected directly by gas sparger at the designed place. In this situation, the oxidation effect could only be significant in its impact radius, which was near the injection point (Mccray and Falta 1996, Yao et al. 2020). Some studies combine ozone with surfactants to extend the impact range, such as sodium dodecyl benzene sulfonate (Kim et al. 2004), while the addition of surfactants would also cause secondary pollution.

Bubbles with a diameter between $200 \mathrm{~nm}$ and $10 \mu \mathrm{m}$ are usually called micro-nano bubbles (MNBs) (Agarwal et al. 2011). MNBs solutions might be a feasible option for the continuous introduction of gaseous oxidizing agents to contaminated water. Ozone micro-nano bubble water (OMNBW) was formed by the release of pressurized ozonated water. Compared with water containing ozone $(\mathrm{OW})$, the small radius of MNBs made it more stable in water (Shangguan et al. 2018). In addition, MNBs had large specific surface area and high interior gas pressure, which was related to the high mass transfer rate of ozone from the gas phase to the liquid phase as well as the high gas dissolution capability (Ikeura et al. 2011, Li et al. 2013, Takahashi et al. 2015). When MNBs shrunk in water, charged ions quickly concentrated and enriched on a very narrow bubble interface, so MNBs had higher zeta potential (Takahashi et al. 2007). MNBs also had stronger migration ability, which had the potential ability to overcome the heterogeneity in porous media (Choi et al. 2008). OMNBW had been proven to be an effective oxidant for the oxidation of various organic pollutants, such as polycyclic aromatic hydrocarbons, chlorinated hydrocarbons and dyes (Hu and Xia 2018, Zhang et al. 2019). However, the oxidation mechanism of OMNBW and the influence of raw water quality was still not clear, which impeded the application of OMNBW in practical engineering.

This paper compared the oxidation efficiency and pathway of aniline by OMNBW and OW, since the formation of MNBs in this study was through the release of pressurized water. The effect of different water quality conditions, such as aniline 
concentration, $\mathrm{pH}$, inorganic ions and dissolved organic matter (DOM), were all studied in this paper. In addition, the oxidation mechanisms of aniline by OW and OMNBW were analyzed through quenching experiment. This paper could help guide the application of OMNBW in wastewater and groundwater treatment engineering.

\section{Materials and methods}

\subsection{Chemicals and reagents}

The chemicals used in the experiment, sodium sulfate (purity $\geq 99 \%$ ), sodium chloride (purity $\geq 99.5 \%$ ), sodium thiosulfate $\left(\mathrm{Na}_{2} \mathrm{~S}_{2} \mathrm{O}_{3}\right)$ (purity $\geq 97 \%$ ) were of analytical grade supplied by Shanghai Lingfeng Chemical Reagent Co. Ltd. Magnesium sulphate (purity $\geq 99 \%$ ) was of analytical grade supplied by Xilong Scientific Co. Ltd. Tert-butyl alcohol (TBA) (purity $\geq 99 \%$ ) was of analytical grade supplied by China National Pharmaceutical Group Co. Ltd. Sodium bicarbonate (purity $\geq 99 \%$ ), indigo disulfonate (purity $\geq 99 \%$ ), $p$-benzoquinone ( $p$-BQ) (purity $\geq$ 98\%), fulvic acid (FA, purity $\geq 85 \%$ ), furfuryl alcohol (purity $\geq 98 \%$ ), humic acid (HA, purity $\geq 90 \%$ ) were of analytical grade supplied by Shanghai Macklin Biochemical Co. Ltd.

\subsection{Production of OMNBW and OW}

OMNBW was created by a continuous OMNBW generation apparatus (HG-WNF1, Hangzhou Guiguan Company, China). Ozone was generated from air in the ozone generator. As shown in Fig. 1, the simulated tap water and the air containing ozone were fed into the saturator at the flow rate of $360 \mathrm{~mL} / \mathrm{min}$ and $140 \mathrm{~mL} / \mathrm{min}$, respectively. The ozonized water was pressurized to $300 \mathrm{kPa}$ in the air saturator, and it was then released into the liquid storage tank with the volume of $12.5 \mathrm{~L}$ through the release head. The water in the liquid storage tank was controlled at $10{ }^{\circ} \mathrm{C}$ through ice bath. Stable dissolved ozone concentration at $1.36 \mathrm{mg} / \mathrm{L}$ could be obtained by aerating for about 5 min in the liquid storage tank. 


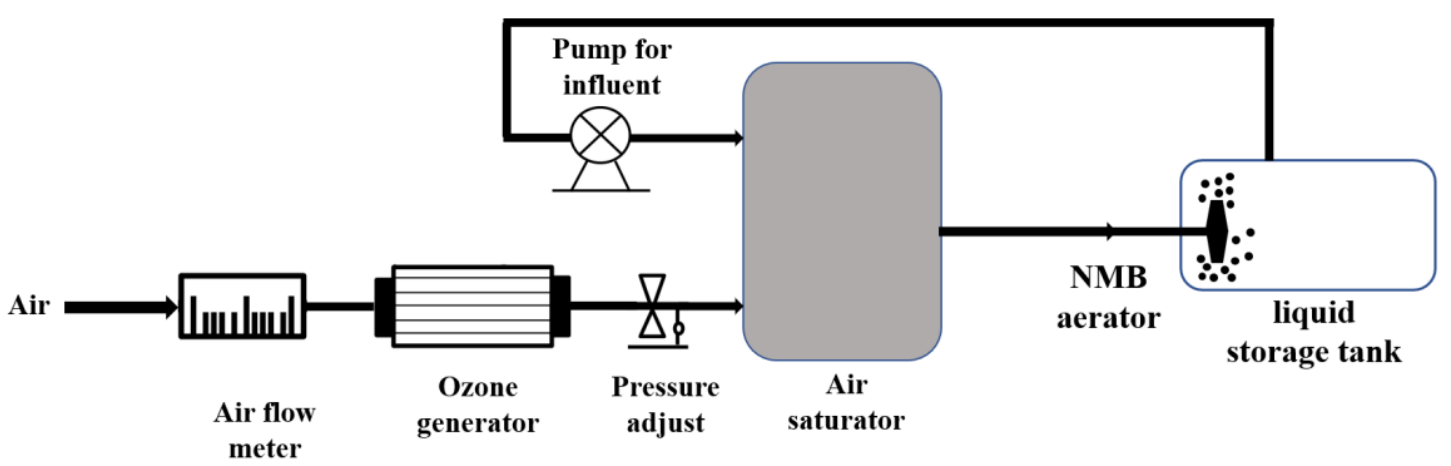

Fig. 1. Schematic diagram of OMNBW generation apparatus

OW was produced by bubbling air containing ozone into water in a cylinder with its volume of $1 \mathrm{~L}$ through a microporous diffuser, in which ozonized air was produced by an ozone generator (FL-803A, China). Ice was also added in water before aeration to control its temperature at $10^{\circ} \mathrm{C}$. The aeration process kept for about 3 min to reach the stable ozone concentration at $1.36 \mathrm{mg} / \mathrm{L}$.

\subsection{Aniline oxidation experiment}

When the aniline oxidation experiment by OMNBW and OW was carried out, 140 $\mathrm{mL}$ aniline solution with the temperature of $10^{\circ} \mathrm{C}$ and a rotator were added in a conical flask of $280 \mathrm{~mL}$ before the addition of OMNBW, and the conical flask was placed on a magnetic stirrer with the rotating speed of $200 \mathrm{rpm} .140 \mathrm{~mL}$ OMNBW or OW were scooped from the liquid storage tank or cylinder and quickly poured into the conical flask. Then the flask was quickly sealed by the rubber stopper. The rubber stopper had two holes, in which one hole was connected with a syringe with its volume of $100 \mathrm{~mL}$ to balance the pressure, and the other hole was connected with the sampling port. 10 $\mathrm{mL}$ water in the flask was sampled each time by gastight syringe at various time intervals up to $5 \mathrm{~min}$. The obtained water sample was quenched by adding $1 \mathrm{~mL}$ $\mathrm{Na}_{2} \mathrm{~S}_{2} \mathrm{O}_{3}$ solution with its concentration of $0.1 \mathrm{M}$, and then it was filtered by the 0.22 $\mu \mathrm{m}$ membrane for detection.

The influence of $\mathrm{pH}$ on the degradation of aniline by ozonation was investigated by adding $\mathrm{H}_{2} \mathrm{SO}_{4}$ or $\mathrm{NaOH}$ solution with its concentration of $0.01 \mathrm{M}$ to adjust $\mathrm{pH}$ between 5.0 and 9.0. When the effect of ions was considered, $250 \mathrm{mg} / \mathrm{L} \mathrm{SO}_{4}{ }^{2-}$ 
$\left(\mathrm{Na}_{2} \mathrm{SO}_{4}\right), 200 \mathrm{mg} / \mathrm{L} \mathrm{HCO}_{3}^{-}\left(\mathrm{NaHCO}_{3}\right), 250 \mathrm{mg} / \mathrm{L} \mathrm{Cl}^{-}(\mathrm{NaCl})$ or $450 \mathrm{mg} / \mathrm{L} \mathrm{Mg}^{2+}$

$\left(\mathrm{MgSO}_{4}\right)$ was mixed with aniline solution individually before the oxidation process.

When the effect of dissolved organic matter was considered, humic acid (HA) or fulvic acid (FA) with its concentration of $50 \mathrm{mg} / \mathrm{L}$ was added to the aniline solution. The mixed solution was stirred evenly by the magnetic stirrer before the oxidation experiment.

In the quenching experiments, sodium thiosulfate, TBA or $p$-BQ was first mixed with aniline solution individually, and the mixed solution was stirred evenly. The molar ratios of sodium thiosulfate, TBA and $p$-BQ to aniline were 1330:1, 1256:1 and 860:1 respectively in order to completely quench the objective reaction. The decomposition kinetics of ozone in OMNBW and OW were also carried out in this paper. In this experiment, OMNBW or OW with its volume of $280 \mathrm{~mL}$ was added directly into the same conical flask, and then the solution was sampled by gastight syringe at various time intervals up to $40 \mathrm{~min}$. Unless specified, all experiments were carried out when the initial aniline concentration was $1 \mathrm{mg} / \mathrm{L}$, temperature was $10^{\circ} \mathrm{C}$, pH was 8.0 and stirring speed was $200 \mathrm{rpm}$. All experiments were conducted in duplicate.

\subsection{Analytical methods}

The ozone concentration of OMNBW and OW was monitored using the indigo method (Wang et al. 2019). Briefly, $1 \mathrm{~mL}$ indigo solution with its concentration of 1.25 $\mathrm{mM}$ and $10 \mathrm{~mL}$ sample solution was mixed in a glass colorimetric tube. The absorption measurements for the indigo method were performed at the wavelength of $610 \mathrm{~nm}$ on a spectrophotometer (SG1000, China).

The aniline concentration was measured by high performance liquid chromatography (HPLC) (Waters e2695, USA) with a C18 column $(4.6 \times 150 \mathrm{~mm}, 5$ $\mu \mathrm{m})$. The mobile phase was an aqueous mixture (40\% methanol and $60 \%$ water) at a flow rate of $1 \mathrm{~mL} / \mathrm{min}$. The injection volume was $10 \mu \mathrm{L}$, and the liquid sample was measured at the wavelength of $233 \mathrm{~nm}$. 


\subsection{The kinetics of ozone self-decomposition}

The pseudo first-order kinetic model could be used to show the difference of selfdecomposition rate between OMNBW and OW as Eq. (1).

$167 \frac{d C}{d t}=-k_{1} C$

168

where $C$ was the dissolved ozone concentration $(\mathrm{mg} / \mathrm{L}), k_{l}$ was the first-order decomposition coefficient $\left(\mathrm{s}^{-1}\right), t$ was the reaction time (s). Eq. (1) could be integrated to obtain the following equation:

$\ln \frac{C_{t}}{C_{0}}=-k_{1} t$

where $C_{t}$ was the dissolved ozone concentration at time $t(\mathrm{mg} / \mathrm{L}), C_{0}$ was the initial dissolved ozone concentration $(\mathrm{mg} / \mathrm{L})$. The decomposition of ozone in OMNBW and OW systems was shown in Fig. 2.

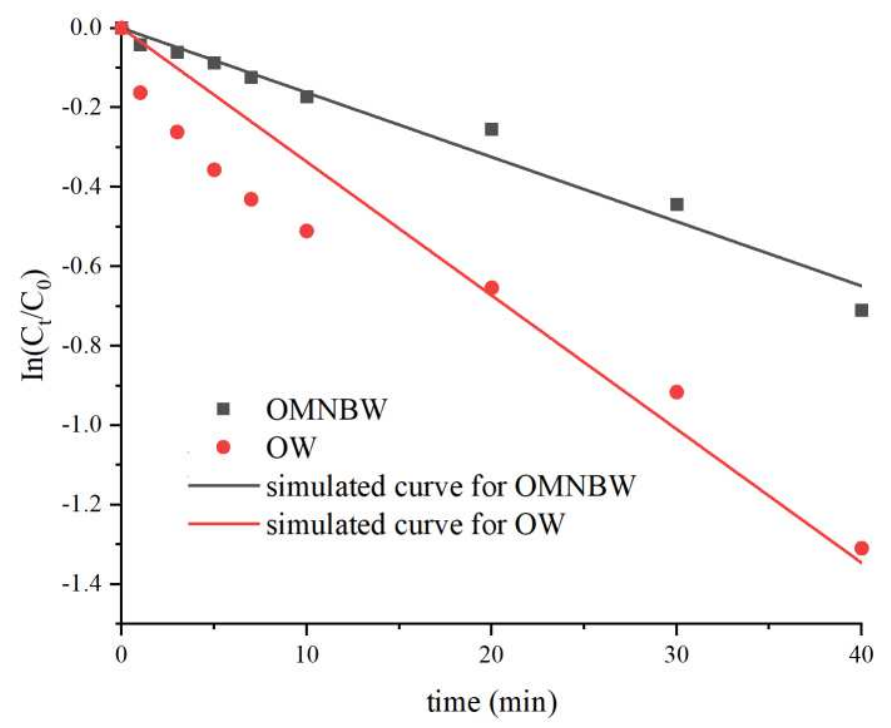

Fig. 2. Ozone self-decomposition curve in OMNBW and OW

The $k_{l}$ value for OMNBW and OW were $0.016 \mathrm{~min}^{-1}$ and $0.033 \mathrm{~min}^{-1}$ respectively, which showed that the self-decomposition of ozone in OMNBW was much slower than that in OW. Previous studies showed that the half-life of ozone in the gas phase was about twice longer than that in the liquid phase (Derco et al. 2021). When pressurized 
water containing ozone was released into the tank, a large fraction of ozone in OMNBW still existed in the gas phase, and then gradually dissolved in water with the disappearance of bubbles (Fujioka et al. 2021), which led to a longer half-life of ozone in OMNBW. The slow release of ozone from gas phase to the liquid phase induced a slower but longer reaction rate between ozone and target contaminants.

\subsection{The aniline oxidation kinetics by OMNBW and OW}

The reaction of ozone and organic substance in aqueous media could be described by the direct molecular reaction by ozone molecules and indirect reaction by hydroxyl radicals $(\bullet \mathrm{OH})($ Hamdi El Najjar et al. 2013). Fig. 3 showed that both OMNBW and OW could oxidize aniline within $30 \mathrm{~s}$, which could be deemed as an instantaneous reaction. Turhan and Uzman (2010) found that when aniline was oxidized by ozone in a bubble column, it was completely degraded within $30 \mathrm{~min}$. Aeration by air bubbles containing ozone required the accumulation of ozone in water, while the direct oxidation by $\mathrm{OW}$ could obtain a very high ozone concentration at the start of reaction, which led to the instantaneous degradation of aniline within $30 \mathrm{~s}$ in this study.

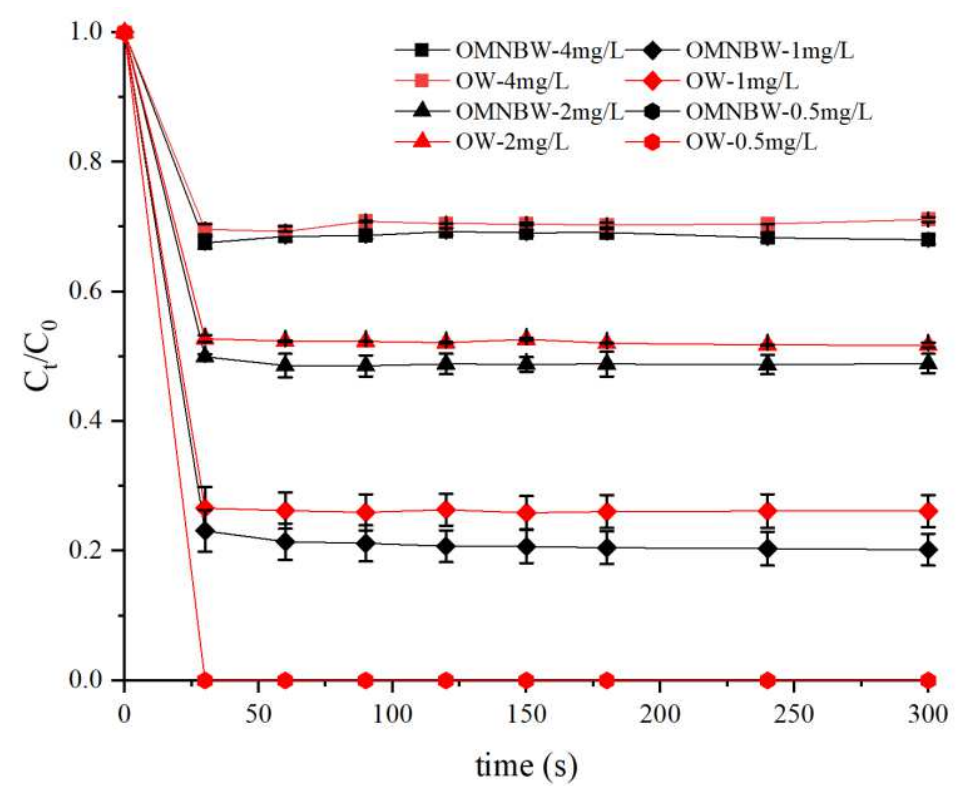

Fig. 3. Degradation of aniline by $O W$ and OMNBW with different initial aniline concentrations

When the initial aniline concentration was $0.5 \mathrm{mg} / \mathrm{L}$, aniline was completely 
degraded within $30 \mathrm{~s}$ by both OMNBW and OW. When the initial aniline concentration was $1 \mathrm{mg} / \mathrm{L}$, the degradation rate of aniline by OMNBW reached $79.8 \%$ in $5 \mathrm{~min}$, which was $5.9 \%$ higher than that by OW. When the initial aniline concentrations were $2 \mathrm{mg} / \mathrm{L}$ and $4 \mathrm{mg} / \mathrm{L}$, the degradation rate by OMNBW were $51.1 \%$ and $32 \%$, which were $2.8 \%$ and $3.1 \%$ higher than that by OW respectively. The results showed that although aniline could react with ozone molecules directly, the removal rate of aniline by OMNBW was still higher than that by OW when the dissolved ozone concentration was the same. Previous studies showed that MNBs would release a large amount of $\bullet \mathrm{OH}$ in the process of annihilation (Liu et al. 2016). At the same time, MNBs had small size and large specific surface area (Agarwal et al. 2011). Therefore, MNBs could adsorb more contaminants and increase the oxidation rate, which finally induced a higher removal rate of aniline in this study.

\subsection{Influence of pH}

It could be observed from Fig. 4 that the degradation rate of aniline by OMNBW or OW both decreased significantly with the increase of $\mathrm{pH}$. Theoretically, during the oxidation process of organic substances by ozone, alkaline conditions would be beneficial to the degradation of contaminants than acidic conditions, because alkaline environment would produce more $\cdot \mathrm{OH}$ that would oxidize contaminants without selectivity (Remucal et al. 2020). In addition, a higher $\mathrm{pH}$ would also increase the lifetime of MNBs, because MNBs became more negative and had stronger repulsive force (Hamamoto et al. 2018). However, the higher $\mathrm{pH}$ during ozonation would also lead to the instability of ozone molecules (Derco et al. 2021), which further resulted in the quick decrease of aqueous ozone concentration.

In alkaline environment, molecular ozone would easily decompose to $\bullet \mathrm{OH}$, which had a very short survival time with the half-life of $10^{-3} \mu$ s (Mei et al. 2019). If it did not contact pollutants for the first time, $\bullet \mathrm{OH}$ would die out and may reduce the ozone utilization rate. Therefore, the aniline oxidation rate by OW decreased from $83.3 \%$ to $69.3 \%$ when $\mathrm{pH}$ increased from 5 to 9 . However, $\mathrm{MNBs}$ would produce much $\bullet \mathrm{OH}$ in 
the process of annihilation (Liu et al. 2016), which could degrade aniline effectively. In addition, the surface of MNBs were negative charged, and MNBs had small size and large specific surface area (Agarwal et al. 2011), which could effectively adsorb pollutants. Therefore, the degradation rate of aniline by OMNBW when $\mathrm{pH}$ was 9 was only $1.3 \%$ lower than that when $\mathrm{pH}$ was 8 (Fig. $4 \mathrm{~b}$ ), which indicated that the oxidation of aniline by OMNBW was less affected by the solution $\mathrm{pH}$ when compared with OW.
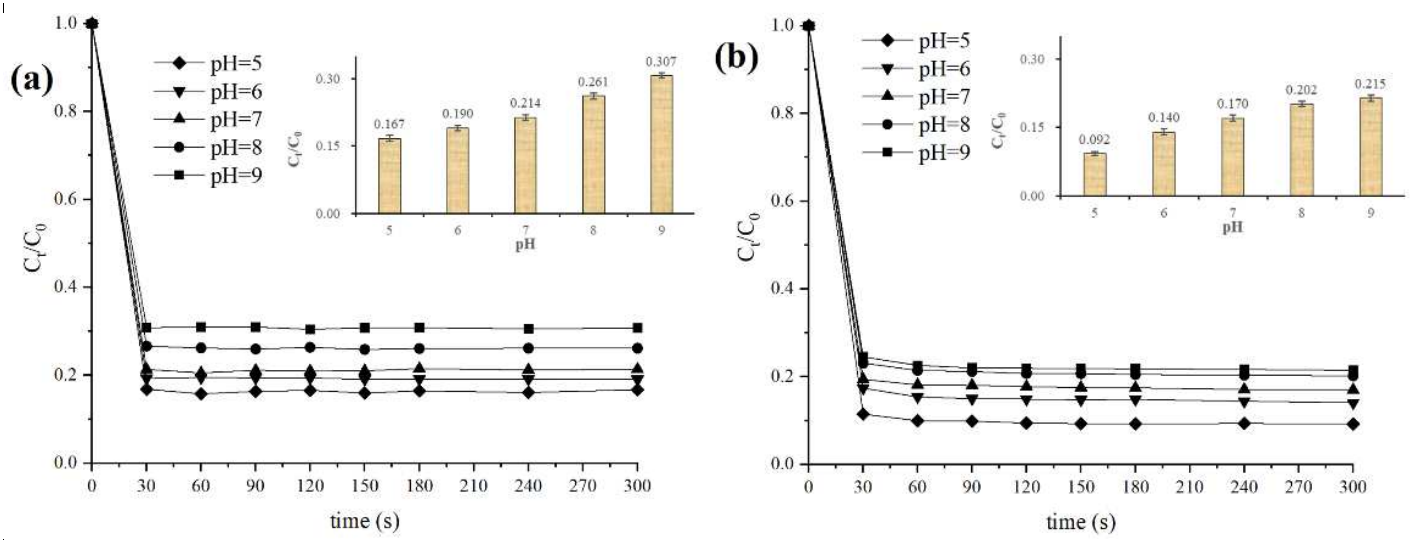

Fig. 4. Influence of $\mathrm{pH}$ on aniline degradation (a: OW; b: OMNBW)

\subsection{Influence of inorganic ions}

Different anions had different influence on ozone oxidation effect (Ji et al. 2018). In this paper, the influence of common ions on the degradation of aniline by OMNBW and $\mathrm{OW}$ was investigated, which included $\mathrm{SO}_{4}{ }^{2-}, \mathrm{Cl}^{-}, \mathrm{HCO}_{3}{ }^{-}$and $\mathrm{Mg}^{2+}$ that were representative ions in the raw water (Santafé-Moros and Gozálvez-Zafrilla 2010). As shown in Fig. 5a, $\mathrm{SO}_{4}{ }^{2-}, \mathrm{Cl}^{-}$and $\mathrm{HCO}_{3}{ }^{-}$only reduced the degradation efficiency by $0.04 \%, 0.99 \%$ and $0.42 \%$ respectively for $\mathrm{OW}$, which was related to the direct oxidation of aniline by molecular ozone. For OMNBW, $\mathrm{SO}_{4}{ }^{2-}$ inhibited the degradation rate of aniline by $1.1 \%$, but $\mathrm{Cl}^{-}$and $\mathrm{HCO}_{3}{ }^{-}$inhibited the degradation rate by $6.4 \%$ and $4.1 \%$ respectively, which showed that these three anions had a relatively significant influence on the oxidation of aniline by OMNBW. According to previous studies, $\mathrm{HCO}_{3}{ }^{-}$and $\mathrm{Cl}^{-}$ were well-known free radical inhibitors and had been widely used for $\bullet \mathrm{OH}$ scavenging (Clarizia et al. 2017, Liu et al. 2013). Therefore, the inhibition of $\mathrm{Cl}^{-}$and $\mathrm{HCO}_{3}{ }^{-}$on OMNBW might be through the inhibition of free radical pathway. However, OW did not form as much $\bullet \mathrm{OH}$ as OMNBW (Liu et al. 2016), so the inhibition by $\mathrm{HCO}_{3}{ }^{-}$and 
$\mathrm{Cl}^{-}$were not significant for OW.

It could also be observed from Fig. 5 that $\mathrm{Mg}^{2+}$ inhibited the $\mathrm{OW}$ oxidation rate by $10.4 \%$, but it only inhibited the OMNBW oxidation rate by $1.5 \%$. The effects of $\mathrm{Mg}^{2+}$ on ozone oxidation pollutants were mainly divided into two aspects. $\mathrm{Mg}^{2+}$ could promote the production of $\cdot \mathrm{OH}$ and had complexation with some ozonation intermediates such as carboxylic acids, so that these intermediates were easier to be oxidized (Sui et al. 2010). In addition, $\mathrm{Mg}^{2+}$ could promote the decomposition of ozone and inhibit the degradation efficiency of contaminant (Rischbieter et al. 2000, Sui et al. 2010), which was consistent with the aniline oxidation results by OW. However, $\mathrm{Mg}^{2+}$ has less inhibition on aniline degradation efficiency by OMNBW. It might be caused by the negatively charged bubbles that could preferentially adsorb $\mathrm{Mg}^{2+}$ (Agarwal et al. 2011), which reduced the catalytic effect of $\mathrm{Mg}^{2+}$ on dissolved ozone. In addition, bubbles also inhibited the direct contact between gas-phase ozone and $\mathrm{Mg}^{2+}$, which prolonged the ozone lifetime at the same time.
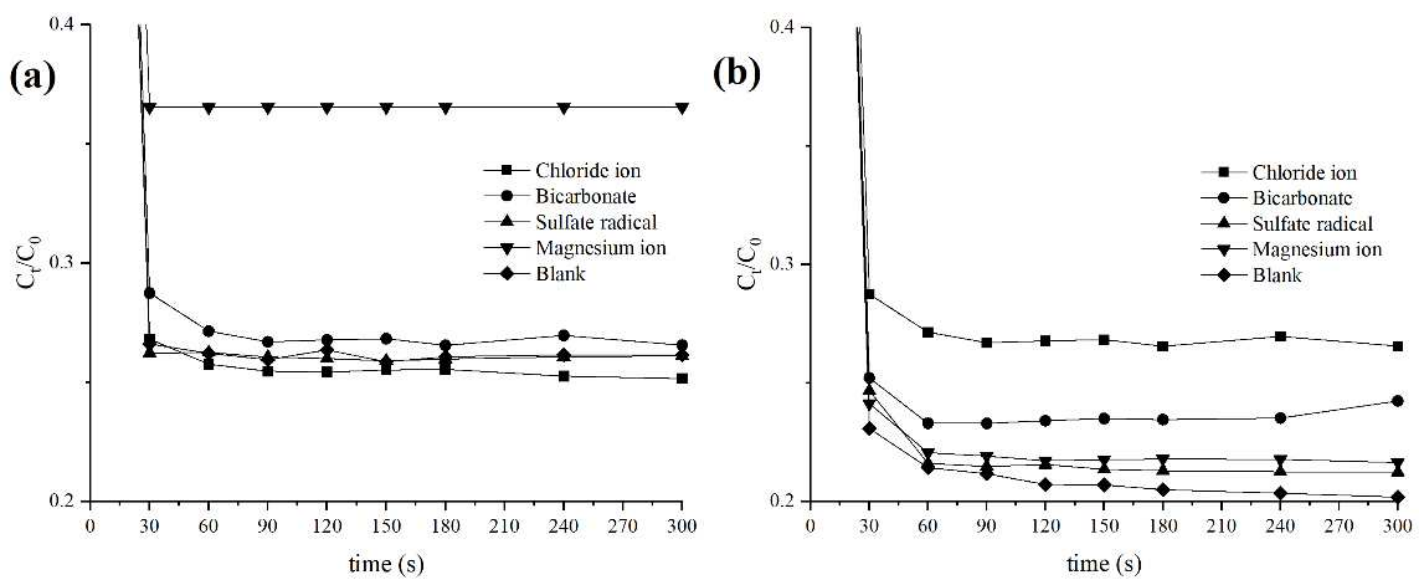

Fig. 5. Influence of different ions on aniline oxidation (a: OW; b: OMNBW)

\section{7}

\subsection{Influence of DOM}

The influence of HA and FA on aniline oxidation by OMNBW and OW was shown in Fig. 6, which showed that both HA and FA had great inhibition effects on the oxidation of aniline by OMNBW and OW. When HA was added in the solution, the degradation rate of aniline by OW and OMNBW decreased by $35 \%$ and $41 \%$, while FA inhibited the aniline degradation rate by $49 \%$ and $62 \%$ respectively, indicating that FA 
with small molecules would react with oxidants more easily (Wang et al. 2017). According to previous research, HA and FA could be oxidized by ozone, which competed with aniline and reduced the aniline oxidation rate as well (Wang et al. 2020). The ozone oxidation mechanism by OMNBW was mainly divided into the direct oxidation by molecular ozone dissolved in water and the "interface degradation" after pollutants were adsorbed on bubbles. DOM with a high concentration would be adsorbed by bubbles and covered the bubble surface, which competed for limited adsorption sites. Therefore, the existence of DOM would inhibit the oxidation of aniline by the competed adsorption and oxidation. It could be inferred that for OMNBW, the oxidation of contaminants was more relied on the molar concentration of contaminants rather than the chemical reaction rate. In OMNBW, contaminants were more easily degraded when they were adsorbed on bubble surface. Both the adsorption capacity of contaminants on bubble surface and the molar concentration of contaminants would affect the ozone oxidation rate, which improved the oxidation selectivity of ozone by

OMNBW.
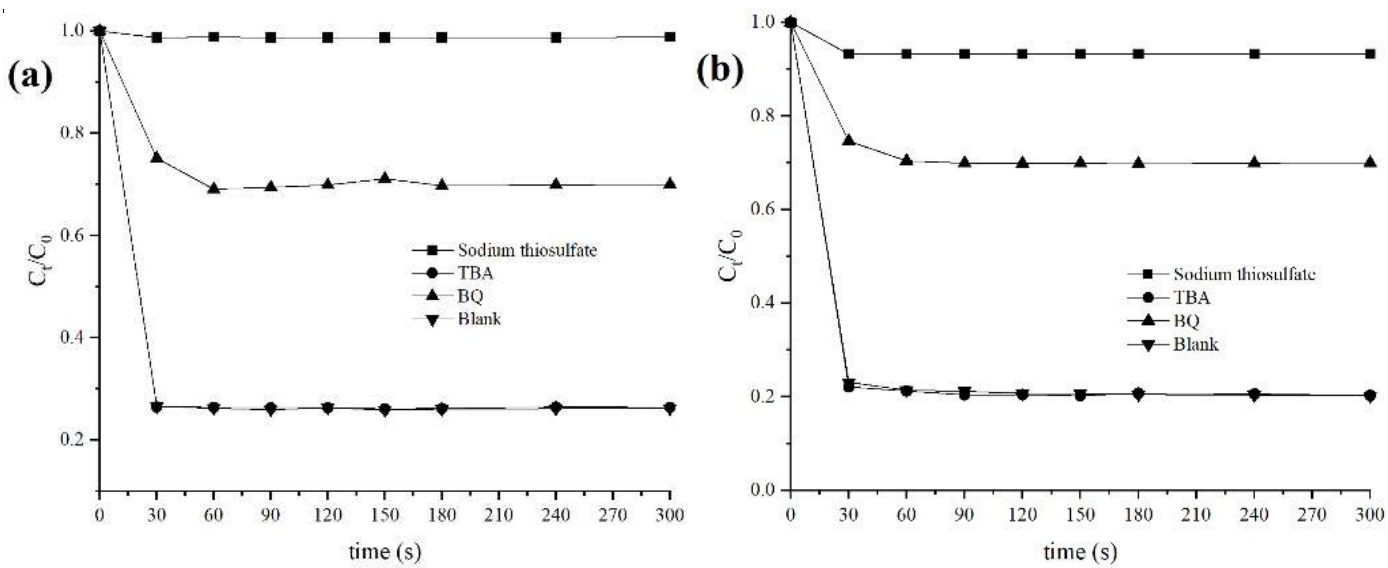

Fig. 6. Influence of DOM on aniline degradation (a: OW; b: OMNBW)

290

\subsection{The oxidation pathways by free radicals}

Previous data in Section 3.2 showed that at the same dissolved ozone concentration, OMNBW had a stronger removal rate of aniline than OW, which might be caused by the free radicals that was formed in OMNBW. TBA was very easy to react with $\bullet \mathrm{OH}$ $\left(k_{\mathrm{TBA}-\cdot \mathrm{OH}}=6.0 \times 10^{8} \mathrm{M}^{-1} \mathrm{~s}^{-1}\right)$, but it hardly reacted with ozone $\left(k_{\mathrm{TBA}-\mathrm{O} 3}=3.0 \times 10^{-3} \mathrm{M}^{-1} \mathrm{~s}^{-}\right.$ 
1) (Nawrocki 2013, Nawrocki and Kasprzyk-Hordern 2010). Therefore, TBA was applied to identify the existence of $\cdot \mathrm{OH}$ in OMNBW and OW. Fig. 7 showed that the aniline oxidation rate by $\mathrm{OW}$ only decreased by $0.30 \%$ after the addition of TBA as scavenger, while the oxidation rate by OMNBW only decreased by $0.15 \%$. It indicated that indirect pathway by $\bullet \mathrm{OH}$ took a very small fraction in the aniline oxidation process. In addition, previous studies reported that TBA tended to disperse in aqueous solution and was not efficient in capturing radicals near bubble surface (Yao et al. 2020). Therefore, the reason for the low quenching effect in OMNBW might be the generation of $\bullet \mathrm{OH}$ at the bubble surface rather than in the solution.
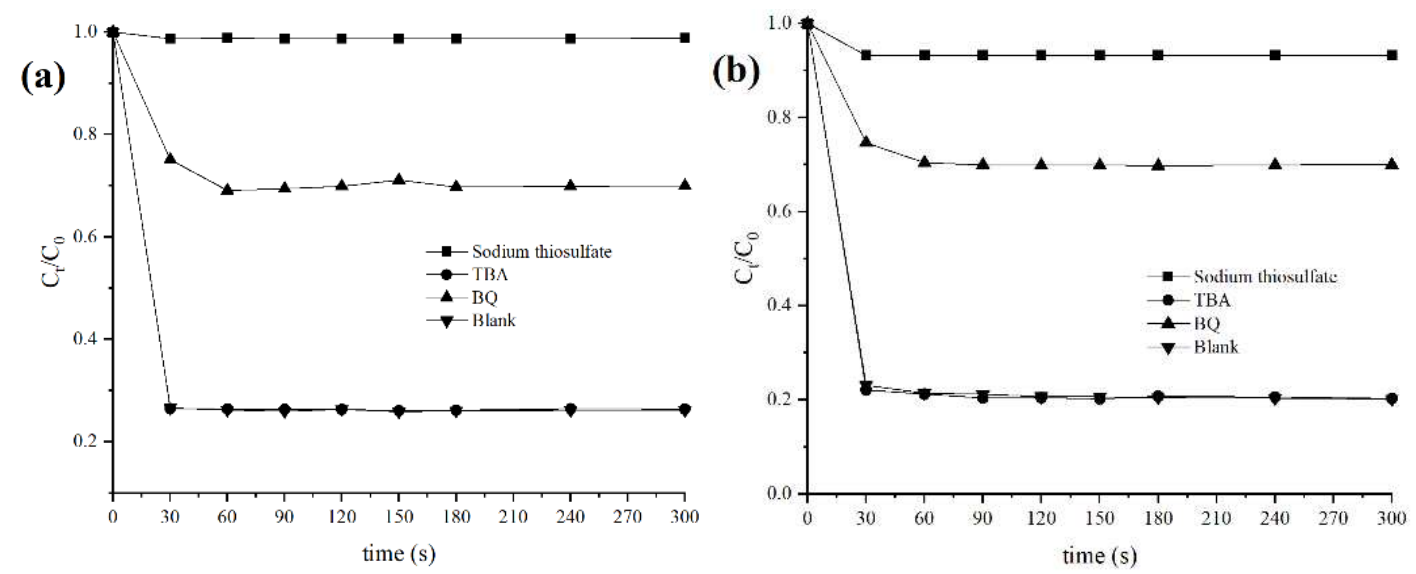

Fig. 7. Effect of free radical on aniline degradation (a: OW; b: OMNBW)

Ozone could initiate free radical chain reactions in water (Acero and Gunten 2001,

Staehelin and Hoigne 1985). These free radical chain reactions played an important role in promoting the decomposition of ozone into various reactive oxygen species (e.g. • $\left.\mathrm{OH}, \mathrm{O}_{2}{ }^{--}, \mathrm{O}_{3}{ }^{*}\right)$ (Guo et al. 2021). Ozone could react with water or hydroxyl ion to produce some primary $\bullet \mathrm{OH}$ and $\mathrm{HO}_{2} \bullet$ (Eqs. 3, 4), and these radicals could further react to form $\mathrm{O}_{2}{ }^{\bullet-}$ (Eq. 5). Once formed, $\mathrm{O}_{2}{ }^{--}$could quickly react with ozone to form $\mathrm{O}_{3}{ }^{\circ-}$ (Eqs. 6, 7). There were increasing studies claiming that $\mathrm{O}_{2}{ }^{--}$was the main reactive oxygen species (ROS) for the removal of ozone-resistant pollutants (Tan et al. 2017,

314 Wang et al. 2016). 
$\mathrm{HO}_{2}{ }^{\bullet} \rightleftharpoons \mathrm{H}^{+}+{ }^{\cdot} \mathrm{O}_{2}$

$\mathrm{O}_{2}{ }^{\cdot-}+\mathrm{O}_{3} \rightarrow \mathrm{O}_{2}+\mathrm{O}_{3}{ }^{--}$

$\mathrm{O}_{3}^{\cdot-} \rightleftharpoons \mathrm{O}_{2}+\mathrm{O}^{\cdot-}$

$p$-BQ was frequently used to trap superoxide radicals $\left(\mathrm{O}_{2}{ }^{--}\right)$with a rate constant of 9.0 9.8 $\times 10^{8} \mathrm{M}^{-1} \mathrm{~s}^{-1}$ (Burns et al. 2012), and $p$-BQ could also react with $\bullet \mathrm{OH}$ with a rate constant of $1.2 \times 10^{9} \mathrm{M}^{-1} \mathrm{~s}^{-1}$ (Burns et al. 2012). However, $p$-BQ hardly reacted with ozone $\left(k_{p-\mathrm{BQ}-\mathrm{O} 3}=2.5 \times 10^{3} \mathrm{M}^{-1} \mathrm{~s}^{-1}\right)($ Mvula and von Sonntag 2003). As the quenching experiment by TBA had proven that $\bullet \mathrm{OH}$ could hardly play any role in the reaction, the effect of $p$-BQ on the aniline oxidation could be attributed to the effect of $\mathrm{O}_{2}{ }^{--}$. Fig. 7 showed that the degradation of aniline by OW was inhibited by $44 \%$ after the addition of $p$-BQ, while the inhibition rate increased to $50 \%$ for OMNBW, indicating that $\mathrm{O}_{2}{ }^{--}$ played important role in the aniline oxidation process. Compared with OW, OMNBW produced more $\mathrm{O}_{2}{ }^{--}$, which indicates that OMNBW could trigger more chain reactions in the degradation of aniline. In addition, when $\mathrm{pH}$ was neutral or alkaline, the indirect oxidation by $\mathrm{O}_{2}{ }^{--}$was the main oxidation pathway (Beltran et al. 1994, Derco et al. 2021).

$\mathrm{Na}_{2} \mathrm{~S}_{2} \mathrm{O}_{3}$ could react with almost all oxidizing substances quickly because of its strong reducibility, so it was often used as an oxidant scavenger (Shen et al. 2008). Fig. 7 showed that the addition of excessive $\mathrm{Na}_{2} \mathrm{~S}_{2} \mathrm{O}_{3}$ almost eliminate the ability of OW to oxidize aniline. However, OMNBW could still oxidize aniline by $7.5 \%$. If it was in homogeneous aqueous solution, excess $\mathrm{Na}_{2} \mathrm{~S}_{2} \mathrm{O}_{3}$ should be able to quickly remove all oxidative substances, which contradicted with the experimental result in this study. The probable reason might be that negatively charged $\mathrm{S}_{2} \mathrm{O}_{3}{ }^{2-}$ could not be effectively adsorbed by negatively charged micro-nano bubbles (Li et al. 2014). On the contrary, bubbles could effectively adsorb positively charged aniline molecules, resulting in the 
oxidation reaction of aniline by ozone at the bubble interface, which led to the aniline oxidation process.

\section{Conclusion}

In this paper, batch experiments were carried out to research the influence factors and oxidation mechanism of aniline oxidation by OW and OMNBW. Experimental results showed that the half-life of ozone in OMNBW was 106\% larger than that of OW, which was caused by the prolonged life of ozone in the gas phase in OMNBW. A lower $\mathrm{pH}$ value would induce a higher oxidation efficiency of aniline for both $\mathrm{OW}$ and OMNBW, but the degradation efficiency of OMNBW reduced less than OW when $\mathrm{pH}$ rose from 8 to $9 . \mathrm{SO}_{4}{ }^{2-}, \mathrm{Cl}^{-}$and $\mathrm{HCO}_{3}{ }^{-}$with their concentrations at $5 \sim 10 \mathrm{mM}$ had almost no effect on $\mathrm{OW}$, but they could reduce the oxidation rate by $1.1 \%, 6.4 \%$ and $4.1 \%$ for OMNBW respectively. For OW and OMNBW, $\mathrm{Mg}^{2+}$ could inhibit the aniline oxidation rate by $10.4 \%$ and $1.5 \%$, respectively. For OW and OMNBW, the addition of HA could decrease the removal rate of aniline by $35 \%$ and $41 \%$, while the ratios were $49 \%$ and $62 \%$ for FA. When OW acted as the oxidant, hydroxyl radical, superoxide radical and molecular ozone contributed $0.3 \%, 43.7 \%$ and $56.0 \%$ for aniline oxidation, while for OMNBW these ratios were $0.2 \%, 49.8 \%$ and $50.0 \%$ respectively. The addition of excessive sodium thiosulfate completely inhibited the oxidation of aniline by OW, but aniline was still oxidized by $7.5 \%$ in the OMNBW system, indicating the interfacial oxidation of aniline in bubble surface. This paper provided a strong support for the application of OMNBW in wastewater and groundwater treatment engineering.

\section{Statements and Declarations}

\section{Funding}

This paper was supported by the National Natural Science Foundation of China (No. 42107261), the Open Project Foundation from Zhejiang Key Laboratory of Urban Environmental Processes and Pollution Control (No. NUEORS202001), and the Program for the Introduction of Talents in Zhejiang Gongshang University (No. 


\section{$374 \quad$ Ethical approval}

Not applicable

376

\section{Competing interests}

The authors have no relevant financial or non-financial interests to disclose.

\section{Consent to participate}

All participates agreed to participate in this study and signed the informed consents.

\section{Consent to publish}

All authors reviewed and approved the manuscript for publication.

\section{Author contributions}

ZX did the aniline oxidation experiment, and wrote the original draft of the paper. JS, YL and LL all offered valuable suggestions for the manuscript. DS helped form the experimental plan, guided the experiment, and offered valuable suggestions for the manuscript. SQ guided the experiment, revised the manuscript and obtained funding for the study.

\section{Data availability}

The datasets used and analyzed during the current study are available from the corresponding author on reasonable request.

\section{References}

Acero JL, Gunten UV (2001) Characterization of oxidation processes: Ozonation and the AOP $\mathrm{O}_{3} / \mathrm{H}_{2} \mathrm{O}_{2}$. J Am Water Works Ass 93(10):90-100. https://doi.org/10.1002/j.15518833.2001.tb09311.x

Agarwal A, Ng WJ, Liu Y (2011) Principle and applications of microbubble and nanobubble technology for water treatment. Chemosphere 84(9):1175-1180. https://doi.org/10.1016/j.chemosphere.2011.05.054

Beltran FJ, García-Araya J, Acedo B (1994) Advanced oxidation of atrazine in water-I. Ozonation. Water Res 28(10):2153-2164. https://doi.org/10.1016/0043-1354(94)90027-2

Burns JM, Cooper WJ, Ferry JL, King DW, DiMento BP, McNeill K, Miller CJ, Miller WL, Peake 
BM, Rusak SA, Rose AL, Waite TD (2012) Methods for reactive oxygen species (ROS) detection in aqueous environments. Aquat Sci 74(4):683-734. https://doi.org/10.1007/s00027012-0251-x

Choi YJ, Park JY, Kim Y J, Nam K (2008) Flow characteristics of microbubble suspensions in porous media as an oxygen carrier. Clean-Soil Air Water 36(1):59-65. https://doi.org/10.1002/clen.200700146

Clarizia L, Russo D, Di Somma I, Marotta R, Andreozzi R (2017) Homogeneous photo-Fenton processes at near neutral pH: A review. Appl Catal B-Environ 209:358-371. https://doi.org/10.1016/j.apcatb.2017.03.011

Derco J, Gotvajn AŽ, Čižmárová O, Dudáš J, Sumegová L, Šimovičová K. (2021) Removal of micropollutants by ozone-based processes. Processes 9(6):1013. https://doi.org/10.3390/pr9061013

Fujioka S, Mizuno K, Terasaka K (2021) Dissolution and shrinking of a single microbubble in stationary liquid with surfactants. Chem Ing Tech 93(1-2):216-222. https://doi.org/10.1002/cite.202000144

Guo Y, Zhang Y, Yu G, Wang Y (2021) Revisiting the role of reactive oxygen species for pollutant abatement during catalytic ozonation: The probe approach versus the scavenger approach. Appl Catal B-Environ 280:119418. https://doi.org/10.1016/j.apcatb.2020.119418

Hamamoto S, Takemura T, Suzuki K, Nishimura T (2018) Effects of pH on nano-bubble stability and transport in saturated porous media. J Contam Hydrol 208: 61-67. https://doi.org/10.1016/j.jconhyd.2017.12.001

Hamdi El Najjar N, Touffet A, Deborde M, Journel R, Leitner NK (2013) Levofloxacin oxidation by ozone and hydroxyl radicals: kinetic study, transformation products and toxicity. Chemosphere 93(4):604-611. https://doi.org/10.1016/j.chemosphere.2013.05.086

Hou L, Zhang H, Xue X (2012) Ultrasound enhanced heterogeneous activation of peroxydisulfate by magnetite catalyst for the degradation of tetracycline in water. Sep Purif Technol 84:147152. https://doi.org/10.1016/j.seppur.2011.06.023

Hu L, Xia Z (2018) Application of ozone micro-nano-bubbles to groundwater remediation. J Hazard Mater 342:446-453. https://doi.org/10.1016/j.jhazmat.2017.08.030

Huang Q, Zhang J, He Z, Shi P, Qin X, Yao W (2017) Direct fabrication of lamellar self-supporting $\mathrm{Co}_{3} \mathrm{O}_{4} / \mathrm{N} / \mathrm{C}$ peroxymonosulfate activation catalysts for effective aniline degradation. Chem Eng J 313:1088-1098. https://doi.org/10.1016/j.cej.2016.11.002

Ikehata K, Gamal El-Din M, Snyder SA (2008) Ozonation and advanced oxidation treatment of emerging organic pollutants in water and wastewater. Ozone-Sci Eng 30(1):21-26. https://doi.org/10.1080/01919510701728970

Ikeura H, Kobayashi F, Tamaki M (2011) Removal of residual pesticides in vegetables using ozone microbubbles. J Hazard Mater 186(1):956-959. https://doi.org/10.1016/j.jhazmat.2010.11.094

Ji H, Gong Y, Duan J, Zhao D, Liu W (2018) Degradation of petroleum hydrocarbons in seawater by simulated surface-level atmospheric ozone: Reaction kinetics and effect of oil dispersant. Mar Pollut Bull 135:427-440. https://doi.org/10.1016/j.marpolbul.2018.07.047

Kim H, Soh HE., Annable MD, Kim DJ (2004) Surfactant-enhanced air sparging in saturated sand. Environ Sci Technol 38(4):1170-1175. https://doi.org/10.1021/es030547o 
Li H, Hu L, Song D, Al-Tabbaa A (2013) Subsurface transport behavior of micro-nano bubbles and potential applications for groundwater remediation. Int J Environ Res Public Health 11(1):473486. https://doi.org/10.3390/ijerph110100473

Li H, Hu L, Song D, Lin F (2014) Characteristics of micro-nano bubbles and potential application in groundwater bioremediation. Water Environ Res 86(9):844-851. https://doi.org/10.2175/106143014x14062131177953

Li X, Schwartz F (2005) Subsurface Contamination Remediation, pp. 82-95. https://doi.org/10.1021/bk-2005-0904.ch004

Liu S, Oshita S, Kawabata S, Makino Y, Yoshimoto T (2016) Identification of ROS produced by nanobubbles and their positive and negative effects on vegetable seed germination. Langmuir 32(43):11295-11302. https://doi.org/10.1021/acs.langmuir.6b01621

Liu X, Zhang T, Zhou Y, Fang L, Shao Y (2013) Degradation of atenolol by UV/peroxymonosulfate: kinetics, effect of operational parameters and mechanism. Chemosphere 93(11):2717-2724. https://doi.org/10.1016/j.chemosphere.2013.08.090

Liu Z, Kanjo Y, Mizutani S (2009) Removal mechanisms for endocrine disrupting compounds (EDCs) in wastewater treatment - physical means, biodegradation, and chemical advanced oxidation: a review. Sci Total Environ 407(2):731-748. https://doi.org/10.1016/j.scitotenv.2008.08.039

Mccray J, Falta R (1996) Defining the air sparging radius of influence for groundwater remediation. J Contam Hydrol 24(1):25-52. https://doi.org/10.1016/0169-7722(96)00005-8

Mei Q, Sun J, Han D, Wei B, An Z, Wang X, Xie J, Zhan J, He M (2019) Sulfate and hydroxyl radicals-initiated degradation reaction on phenolic contaminants in the aqueous phase: Mechanisms, kinetics and toxicity assessment. Chem Eng J 373:668-676. https://doi.org/10.1016/j.cej.2019.05.095

Miao H, Cao M, Xu D, Ren H, Zhao M, Huang Z, Ruan W (2015) Degradation of phenazone in aqueous solution with ozone: influencing factors and degradation pathways. Chemosphere 119:326-333. https://doi.org/10.1016/j.chemosphere.2014.06.082

Mvula E, von Sonntag C (2003) Ozonolysis of phenols in aqueous solution. Org Biomol Chem 1(10):1749-1756. https://doi.org/10.1039/b301824p

Nawrocki J (2013) Catalytic ozonation in water: Controversies and questions. Discussion paper. Appl Catal B-Environ 142-143:465-471. https://doi.org/10.1016/j.apcatb.2013.05.061

Nawrocki J, Kasprzyk-Hordern B (2010) The efficiency and mechanisms of catalytic ozonation. Appl Catal B-Environ 99(1-2):27-42. https://doi.org/10.1016/j.apcatb.2010.06.033

Neyens E, Baeyens J (2003) A review of classic Fenton's peroxidation as an advanced oxidation technique. J Hazard Mater 98(1-3):33-50. https://doi.org/10.1016/s0304-3894(02)00282-0

Orge C, Faria J, Pereira MFR (2017) Photocatalytic ozonation of aniline with $\mathrm{TiO}_{2}$-carbon composite materials. J Environ 195:208-215. https://doi.org/10.1016/j.jenvman.2016.07.091

Remucal CK, Salhi E, Walpen N, von Gunten U (2020) Molecular-level transformation of dissolved organic matter during oxidation by ozone and hydroxyl radical. Environ Sci Technol 54(16):10351-10360. https://doi.org/10.1021/acs.est.0c03052

Rischbieter E, Stein H, Schumpe A (2000) Ozone solubilities in water and aqueous salt solutions. J 
Chem Eng Data 45(2):338-340. https://doi.org/10.1021/je990263c

Santafé-Moros A, Gozálvez-Zafrilla JM (2010) Nanofiltration study of the interaction between bicarbonate and nitrate ions. Desalination 250(2):773-777. https://doi.org/10.1016/j.desal.2008.11.039

Shangguan Y, Yu S, Gong C, Wang Y, Yang W, Hou L (2018) A review of microbubble and its applications in ozonation. Iop Conference: Earth and Environmental Science 128:012149. https://doi.org/10.1088/1755-1315/128/1/012149

Shen J, Chen Z, Xu Z, Li X, Xu B, Qi F (2008) Kinetics and mechanism of degradation of pchloronitrobenzene in water by ozonation. J Hazard Mater 152(3):1325-1331. https://doi.org/10.1016/j.jhazmat.2007.08.009

Staehelin J, Hoigne J (1985) Decomposition of ozone in water in the presence of organic solutes acting as promoters and inhibitors of radical chain reactions. Environ Sci Technol 19(12):12061213. https://doi.org/10.1021/es00142a012

Sui M, Sheng L, Ma J, Tian F, Lu K (2010) Assistance of magnesium cations on degradation of refractory organic pollutant by ozone: Nitrobenzene as model compound. Ozone-Sci Eng 32(2):113-121. https://doi.org/10.1080/01919510903579460

Takahashi M, Chiba K, Li P (2007) Free-radical generation from collapsing microbubbles in the absence of a dynamic stimulus. J Phys Chem B 111(6):1343-1347. https://doi.org/10.1021/jp0669254

Takahashi M, Horibe H, Matsuura K, Tatera K (2015) Effect of microbubbles on ozonized water for $\begin{array}{llllll}\text { photoresist removal. J Photopolym } & \text { Sci } & \text { Tec 28(2):293-298. }\end{array}$ https://doi.org/10.2494/photopolymer.28.293

Tan X, Wan Y, Huang Y, He C, Zhang Z, He Z, Hu L, Zeng J, Shu D (2017) Three-dimensional $\mathrm{MnO} 2$ porous hollow microspheres for enhanced activity as ozonation catalysts in degradation of bisphenol A. J Hazard Mater 321:162-172. https://doi.org/10.1016/j.jhazmat.2016.09.013

Trautwein G, El Bakkali B, Alcañiz-Monge J, Artetxe B, Reinoso S, Gutiérrez-Zorrilla JM (2015) Dimeric assemblies of lanthanide-stabilised dilacunary Keggin tungstogermanates: A new class of catalysts for the selective oxidation of aniline. $J$ Catal 331:110-117. https://doi.org/10.1016/j.jcat.2015.09.004

Turhan K, Uzman S (2010) The degradation products of aniline in the solutions with ozone and kinetic investigations. Annali Di Chimica 97(10):1129-1138. https://doi.org/10.1002/adic.200790096

Wang Y, Xie Y, Sun H, Xiao J, Cao H, Wang S (2016) Hierarchical shape-controlled mixed-valence calcium manganites for catalytic ozonation of aqueous phenolic compounds. Catal Sci Technol. 6(9): 2918-2929. https://doi.org/10.1039/c5cy01967b

Wang F, Huang Y, Zhuo X, He C, Li Q (2020) Molecular-level transformation characteristics of refractory organics in landfill leachate during ozonation treatment. Sci Total Environ 749:141558. https://doi.org/10.1016/j.scitotenv.2020.141558

Wang H, Wang Y, Lou Z, Zhu N, Yuan H (2017) The degradation processes of refractory substances in nanofiltration concentrated leachate using micro-ozonation. Waste Manage 69:274-280. https://doi.org/10.1016/j.wasman.2017.08.048

Wang J, Quan X, Chen S, Yu H, Liu G (2019) Enhanced catalytic ozonation by highly dispersed 
$\mathrm{CeO}_{2}$ on carbon nanotubes for mineralization of organic pollutants. J Hazard Mater 368:621629. https://doi.org/10.1016/j.jhazmat.2019.01.095

Yao J, Yu Y, Qu R, Chen J, Huo Z, Zhu F, Wang Z (2020) Fe-activated peroxymonosulfate enhances the degradation of dibutyl phthalate on ground quartz sand. Environ Sci Technol 54(14):90529061. https://doi.org/10.1021/acs.est.0c00793

Zabihi-Mobarakeh H, Nezamzadeh-Ejhieh A (2015) Application of supported $\mathrm{TiO}_{2}$ onto Iranian clinoptilolite nanoparticles in the photodegradation of mixture of aniline and 2, 4-dinitroaniline aqueous solution. J Ind Eng Chem 26:315-321. https://doi.org/10.1016/j.jiec.2014.12.003 in situ and targeting remediation of phenanthrene-contaminated sediment-aquifer. Water Res 160:29-38. https://doi.org/10.1016/j.watres.2019.05.043

Zhou Y, Gu X, Zhang R, Lu J (2014) Removal of aniline from aqueous solution using pine sawdust modified with citric acid and $\beta$-cyclodextrin. Ind Eng Chem Res 53(2):887-894. https://doi.org/10.1021/ie403829s 